\title{
OTIOLTOMTS
}

Revista de economía, empresa y sociedad

Dosier "Género y empresa: hacia la igualdad real»

Coordinadora: Laura Lamolla Kristiansen

\section{Una aproximación al género del empresariado}

\section{Dra. Anna Pérez-Quintana}

Profesora de la facultad de Empresa y Comunicación de la Universidad de Vic.

RESUMEN Tradicionalmente, la creación de empresas ha sido un empleo reservado a los hombres, hasta el punto que el número de empresarios que ponen en marcha un negocio dobla al de las empresarias. Esta falta de igualdad no solo es cuantitativa, sino también cualitativa. Más allá de las diferencias biológicas entre ambos sexos, el artículo sondea otras explicaciones -sociológicas-que permitan mejorar la comprensión del porqué de la brecha empresarial de género, así como promover la vocación emprendedora de las mujeres a partir de la toma de conciencia de la posibilidad de revertir este gap.

PALABRAS CLAVE clave emprendimiento, estereotipos de género, intención de emprender.

\section{An analysis of gender in the business world}

ABSTRACT Traditionally, the creation of companies has been a job that is the reserve of men, to the point that the number of male entrepreneurs who start a business doubles that of female entrepreneurs. This lack of equality is not only quantitative, but also qualitative. Beyond the biological differences between both sexes, the article explores other explanations-sociological-which allow for an improvement in understanding the reason for the gender gap in entrepreneurship, as well as allowing for the promotion of the entrepreneurial vocation of women by recognising that there is a possibility to make an impact on this gap.

KEYWORDS entrepreneurship; gender stereotypes; intention of starting a business 


\section{Introducción}

Las desigualdades entre hombres y mujeres existentes en la sociedad se reproducen en el terreno del emprendimiento, más, incluso, cuando se trata de un empleo a menudo vinculado al poder económico y político. Si a lo largo de la historia las mujeres han quedado al margen de las dinámicas del poder, no es extraño comprobar que su presencia entre los cargos de responsabilidad de las empresas o dentro del colectivo del empresariado es todavía minoritaria.

El estudio de esta desigualdad es un tema de indudable interés teniendo en cuenta que las mujeres no son un colectivo, sino que constituyen la mitad de la población. Más aún si tenemos en cuenta que el aumento de la actividad empresarial podría limar la feminización de la pobreza a través de la independencia económica que proporciona su ejercicio, siempre que el negocio que se ponga en marcha sea económicamente sostenible.

Pero estudiar esta actividad económica de las mujeres no es una tarea fácil: para empezar, hay que destacar que en nuestro país no es posible hacer una descripción detallada de la brecha de género en el empresariado a partir del análisis de fuentes primarias de información. Cuando el empresariado realiza los trámites administrativos requeridos por la Agencia Tributaria del Ministerio de Economía y Hacienda para proceder al alta censal de su negocio, no hay ninguna casilla en el Modelo 036 en la que indicar el sexo de la persona que emprende. Por otro lado, la condición de empresario o empresaria ${ }^{1}$ la asume quien pone en marcha un negocio ejerciendo tareas de dirección o gerencia y se da de alta en el Régimen Especial de Trabajadores Autónomos (RETA) o bien en el Régimen General Asimilado de la Seguridad Social; el hecho es que la Muestra Continua de Vidas Laborales (MCVL), proporcionada por el Ministerio de Trabajo y Seguridad Social, informa de manera segregada por sexos en el primer colectivo (los autónomos), pero no en el segundo (Régimen General de Asimilados). El resto de fuentes de información referidas al empresariado, o bien no son de acceso abierto, o bien no están diferenciadas entre mujeres y hombres. Esta carencia informativa confiere al colectivo de las mujeres empresarias una falta de visibilidad estadística que dificulta el estudio en profundidad.

A pesar de la poca calidad de la información proporcionada por las fuentes estadísticas sobre el emprendimiento desde la perspectiva de género, sabemos que el número de empresarios dobla al de empresarias. Este artículo profundiza en las explicaciones aportadas desde la sociología con el objetivo de arrojar luz al porqué de esta desigualdad.

\section{El proceso de socialización y los estereotipos de género}

La socialización a la que se somete al individuo durante su niñez tiene como objetivo encajarlo en la sociedad, y pone en funcionamiento una serie de programas de aprendizaje predefinidos socialmente que, entre otros aspectos, tenderán a explicar las cosas de manera diferente para los niños y las niñas. Mediante el lenguaje, las prácticas discursivas van dibujando los diferentes estereotipos que conseguirán que el individuo logre su identidad.

Los estereotipos se aprenden durante el proceso de socialización y constituyen generalizaciones hacia un determinado grupo de personas que las distinguen de otros grupos, de forma que se les atribuyen una serie de rasgos distintivos que tienen un carácter predictivo. Aunque los estereotipos - de género, clase social, raza, profesión, edad, religión, orientación sexual- son resistentes al cambio, evolucionan, pudiendo variar según el momento y el lugar. Cuando comportan una evaluación negativa del grupo, constituyen prejuicios, y llegan a la discriminación en el momento en que la pertenencia a este grupo comporta recibir un trato negativo.

Los estereotipos de género se refieren a las creencias consensuadas socialmente sobre las características y atributos asociados a cada sexo. Estas características estereotipadas de ambos sexos no solo describen cómo son los hombres y las mujeres (estereotipos descriptivos), también cómo tienen que ser (estereotipos prescrip-

1. Ley 50/1998, de 30 de diciembre, de medidas fiscales, administrativas y de orden social (BOE de 31/12/1998). 
tivos). Durante la socialización primaria que se produce durante la infancia y la adolescencia, y que es llevada a cabo por los padres, la escuela y los medios de comunicación, se alienta la adhesión del individuo a los estereotipos de género. De este modo, la construcción de los estereotipos de género contribuye al mantenimiento del orden social, basado en el androcentrismo y consistente en la visión del mundo que concibe al hombre como centro de la sociedad, la religión y la familia, haciendo menos visible la mujer. A partir del instante del nacimiento de los individuos se produce un fenómeno de valorización social diferente en función del sexo. Así, en la mayoría de las culturas la valorización es más positiva en el caso de los niños que en el de las niñas, lo que sitúa a las mujeres en una posición de desventaja dentro de la sociedad -o estatus inferior- frente a los hombres.

En cuanto a los atributos concretos que caracterizan a los estereotipos de género, hay que decir que existe una serie de rasgos instrumentales o agentes asociados en mayor medida a aquello que es masculino, como la racionalidad, la ambición, la autonomía, el valor, la competencia, la orientación al éxito, la agresividad, la autosuficiencia y la independencia. En cambio, los rasgos expresivos o comunes se asocian con la feminidad, como el respeto a los otros, la expresividad, la capacidad de conexión, la amabilidad, la bondad, el apoyo, la prudencia, la fragilidad, la inestabilidad, la timidez, la ternura, el afecto, las relaciones y la preocupación por lo social. Generalmente, de los hombres se espera que sean proveedores, y de las mujeres, que sean cuidadoras. Además, la vertiente prescriptiva de los estereotipos de género hace que, en términos generales, los rasgos masculinos sean deseables en un hombre e indeseables en una mujer y viceversa.

Hay cuatro tipos de estereotipos de género: masculino, femenino, andrógino y no diferenciado. El proceso de socialización persigue que los hombres se identifiquen con el género masculino y las mujeres con el femenino, pero no siempre lo consigue. Hay hombres femeninos y mujeres masculinas. Además, la identidad de género andrógina la perciben aquellos individuos que se identifican con niveles elevados tanto de rasgos del estereotipo femenino como del masculino. Cuando el nivel de identificación con los estereotipos es bajo, el individuo posee un género no diferenciado.

La orientación de género es un indicador del éxito del proceso de socialización, ya que responde al grado de identificación de los individuos con los estereotipos de género socialmente construidos.

\section{La elección de carrera profesional y la intención de emprender}

La influencia de los estereotipos de género es sutil, poderosa y penaliza a quienes quieren salir de aquello que es prescriptivo. El proceso de socialización de los individuos recurre a una serie de mecanismos que aseguran la división sexual del trabajo, mediante la que es natural que los hombres se dediquen a tareas productivas y las mujeres, a las reproductivas (cuidado de personas dependientes y reproducción doméstica). Además, pone las primeras piedras en el despertar de las vocaciones profesionales y, por lo tanto, la elección de estudios superiores. La segregación entre hombres y mujeres en el mundo laboral es vigente, tanto horizontalmente -todavía hay empleos femeninos y otros masculinos- como verticalmente -ellos ocupan cargos más cualificados y mejor remunerados que ellas-. Afortunadamente, la sociedad evoluciona gracias a que se ponen en entredicho los principios de la socialización, y en algunos aspectos ha habido adelantos significativos, pero en otros, todavía están por llegar.

Por otro lado, la intención emprendedora es un constructo que mide la verdadera voluntad o convicción de una persona de poner en marcha un negocio en algún momento de su vida. Tradicionalmente la creación de empresas ha sido un territorio reservado a los hombres. La prueba es el hecho de que, según la Encuesta de Población Activa del segundo trimestre del 2019 (INE), las mujeres representan aproximadamente un 35,7 \% el empresariado catalán. En otras palabras, los empresarios doblan el número de empresarias. Pero, a las diferencias cuantitativas se le añaden otras cualitativas: las mujeres emprenden de forma abrumadora en el sector servicios (comercio al detalle y hostelería), lo que hace que sean más intensivas en mano de obra que en maquinaria. Las empresas creadas por mujeres son más pequeñas y presentan peores resultados en los indicadores basados en los principios de racionalidad económica o desempeño (facturación, crecimiento, resultado, inversión, internalización). 
El hecho es que la mayor parte de los artículos publicados sobre emprendimiento que adoptan la perspectiva de género se centran en comparar las empresas creadas por los hombres con las creadas por las mujeres. Es decir, para realizar el análisis, se parte de la diferencia biológica o sexual entre el empresariado (empresarios versus empresarias) y como el sexo es difícilmente modificable, lo que se afirma implícitamente desde la academia es que la brecha de género en emprendimiento es natural e irreversible (si se nace mujer, habrá menos probabilidad de crear empresa y, si se crea, logrará un peor desempeño).

Pero, además del sexo (biología: mujer-hombre), también está el género (sociología: masculino-femenino), una construcción cultural que evoluciona según el momento y el lugar en el que nos encontremos. La figura de la persona emprendedora también se construye socialmente y puede evolucionar, a pesar de que la norma en emprendimiento es invisiblemente masculina hasta fecha de hoy. Esto hace que las empresarias no solo constituyan la minoría, sino que, además, presenten peores resultados en la comparativa, ya que, a la hora de elegir un empleo o de ejercerlo, ellas no se ven reflejadas en el arquetipo.

\section{La orientación de género de la persona emprendedora}

Como ya se ha comentado anteriormente, el número de empresarios dobla al de empresarias. La idea que subyace a esta información es que son las diferencias biológicas entre hombres y mujeres las que la explican. Es decir, que el hecho de nacer hombre o mujer determina disponer de mayor o menor propensión hacia el emprendimiento. Si bien es cierto que nunca podremos delimitar exactamente qué parte de nuestras diferencias se deben a la anatomía y cuál a la sociología, lo que sí podemos afirmar es que muchas de estas diferencias se construyen a medida que los agentes socializadores ejercen su influencia en nosotros. En otras palabras, estudios recientes han demostrado que más que el sexo, lo que influye en los individuos a la hora de poner en marcha un negocio es su orientación de género, es decir, el grado de identificación con los estereotipos masculinos, femeninos, andróginos o no diferenciados.

De esta manera, los estudios parten de la selección de 31 ítems que, o bien son sinónimos o bien antónimos de la figura de la persona emprendedora, llegando a los siguientes resultados:

- Los estereotipos de género (EG) persisten. La distribución de los 31 ítems entre los diversos estereotipos es la siguiente:

- EG masculino: seguro de sí mismo, dispuesto a asumir riesgos, dispuesto a posicionarse, individualista, decidido -firme-, con temperamento, independiente, con capacidad de liderazgo, toma decisiones fácilmente, ambicioso, dominante-agresivo, competitivo.

- EG femenino: tímido-discreto, crédulo, flexible, leal, sensible a les necesidades de los otros, sumiso, humilde, amable-atento.

- EG andrógino: creativo, innovador, optimista, analítico, imprevisible, activo -enérgico-, con capacidad de esfuerzo sostenido.

- EG no diferenciado: asertivo, no sistemático, autosuficiente, obediente, defiende con vehemencia sus opiniones, no desea protagonismo.

- La figura de la persona emprendedora se caracteriza tanto por ítems andróginos (creativo, innovador, optimista, activo -enérgico-, con capacidad de esfuerzo sostenido) como masculinos (seguro de sí mismo, dispuesto a asumir riesgos, con capacidad de liderazgo, ambicioso, competitivo).

- Los individuos que se identifican con el género andrógino o masculino muestran una mayor intención de emprender. Las personas con una identidad femenina muestran una débil o nula intención de emprender.

- La orientación de género es una variable que explica mejor que el sexo biológico las cuestiones relacionadas con el emprendimiento. 


\section{Conclusiones}

La figura del empresariado está asociada al estereotipo de género masculino y al andrógino. Ningún ítem femenino define a la persona emprendedora. En consecuencia, la mujer percibe que socialmente no se espera de ella que ponga en marcha una empresa, de manera que sucumbe a la amenaza por el estereotipo actuante tal y como se espera de ella. Esta es una explicación plausible de la brecha de género en la creación de empresas: las mujeres no nacen con menor intención de emprender, sino que es el proceso de socialización el que las lleva a menores niveles de autoeficacia para los negocios.

Por otro lado, la intención de emprender es fruto de las percepciones subjetivas -la identidad de género- más que de las condiciones objetivas -el sexo biológico-. En cuestiones relacionadas con el emprendimiento, hombres y mujeres no pueden ser tratados como grupos homogéneos, ya que las generalizaciones son arriesgadas y nos alejan de la compleja realidad. Hay más diferencias dentro del grupo de los hombres, por un lado, y dentro del grupo de las mujeres, por el otro, que no entre los dos grupos.

Si se potenciara la imagen social de los rasgos andróginos de la persona emprendedora (como la creatividad o la innovación), posiblemente la brecha de género en la creación de empresas se reduciría.

Asimismo, se propone un cambio de paradigma en el que tomen valor determinados rasgos estereotipadamente femeninos como valores positivos para el emprendimiento: la flexibilidad, la sensibilidad hacia las necesidades de los otros, la adaptabilidad, no tienen por qué ser contrarios a la figura de la persona emprendedora. Posiblemente potenciando estos valores llegaríamos a un sistema económico menos destructivo y menos injusto. En la misma línea, determinados rasgos estereotipados como masculinos y deseables en una persona emprendedora también deberían ser deseables en una mujer; la seguridad en sí mismo, la capacidad de liderazgo o el hecho de estar dispuesto a posicionarse. En definitiva, humanizar la economía significa hacerla más inclusiva, promoviendo en la figura de la persona emprendedora aquello que responde a lo mejor de la feminidad y la masculinidad.

La figura del empresariado es una construcción social. Más que nacer, el empresariado se hace, y este es un empleo que tradicionalmente ha estado vetado a las mujeres. La prueba es el hecho de que no hay ningún rasgo del estereotipo de género femenino que identifique a la persona emprendedora. La mayoría de las características son masculinas o andróginas. En consecuencia, la mujer percibe que socialmente no se espera de ella que ponga en marcha una empresa. Y si, a pesar de todo, contempla la posibilidad de hacerlo, ve que tiene que contradecir el estereotipo naturalmente asignado a su sexo, es decir, tiene que salir de la normalidad. Esta es una explicación plausible de la brecha de género en la creación de empresas: las mujeres no nacen con una intención de emprender menor, sino que es el proceso de socialización lo que las lleva a niveles menores de autoeficacia para los negocios. He aquí la importancia de visibilizar a las mujeres que han creado un negocio de éxito, pues esto hará que el estereotipo de género de la persona emprendedora se acerque a rasgos más inclusivos en los que todo el mundo puede verse reflejado.

\section{Bibliografía}

AHL, H. (2006). «Why research on women entrepreneurs needs new directions». Entrepreneurship: Theory \& Practice. Vol. 30, núm. 5, pág. 595-621. https://doi.org/10.1111/j.1540-6520.2006.00138.x.

BEM, S. (1981). Bem sex rol inventory. Professional manual (1 ed.). Palo Alto, CA: Consulting Psychologists Press, Inc.

GUPTA, V.; TURBAN, D. B.; WASTI, S. Ar.; SIKDAR, A. (2009). «The role of gender stereotypes in perceptions of entrepreneurs and intentions to become an entrepreneur». Entrepreneurship: Theory \& Practice. Vol. 33, núm. 2, pág. 397-417. https://doi.org/10.1111/j.1540-6520.2009.00296.x. 
MUELLER, S. L.; CONWAY, M. (2013). "A cross cultural study of gender role orientation and entrepreneurial self-efficacy». International Entrepreneurship and Management Journal. Vol. 9, núm. 1, pág. 1-20. https://doi. org/10.1007/s11365-011-0187-y.

PÉREZ-QUINTANA, A.; HORMIGA, E.; MARTORI, J. C.; MADARIAGA, R. (2017). «The influence of sex and gender-role orientation in the decision to become an entrepreneur». International Journal of Gender and Entrepreneurship. Vol. 9, núm. 1, pág. 8-30. https://doi.org/10.1108/JJGE-12-2015-0047.

Cita recomendada: PÉREZ-QUINTANA, Anna. Una aproximación al género del empresariado. Oikonomics [en línea]. Mayo 2020, no. 13, pp. 1-6. ISSN: 2339-9546. DOI: https://doi.org/10.7238/o.n13.2002

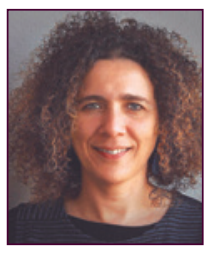

\section{Anna Pérez-Quintana}

anna.perez@uvic.cat

Profesora de la facultad de Empresa y Comunicación y directora de la Unidad de Igualdad de la Universitat de Vic-Universitat Central de Catalunya.

Licenciada y doctora en Ciencias Económicas y Empresariales. Profesora de la Facultad Empresa y Comunicación y directora de la Unidad de Igualdad de la Universitat de Vic-Universitat Central de Catalunya. Miembro del grupo de investigación Societats, Polítiques i Comunitats Inclusives (SoPCl). Imparte docencia en contabilidad de costes y de gestión, así como en dirección de operaciones. Su investigación se centra en las relaciones de las mujeres con la economía y la empresa.

Los textos publicados en esta revista están sujetos -si no se indica lo contrario- a una licencia de Reconocimiento 4.0 Internacional de Creative Commons. Puede copiarlos, distribuirlos, comunicarlos públicamente, hacer obras derivadas siempre que reconozca los créditos de las obras (autoría, nombre de la revista, institución editora) de la manera especificada por los autores o por la revista. La licencia completa se puede consultar en https://creativecommons.org/licenses/by/4.0/deed.es_ES.

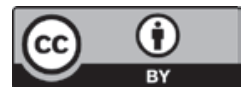

